\title{
Hemolytic Transfusion Reactions
}

\author{
Erwin Strobel \\ Department Medizinische Mikrobiologie, Immunologie und Krankenhaushygiene, Medizet, \\ Städtisches Klinikum München GmbH, Germany
}

\section{Key Words}

Acute hemolytic transfusion reaction - Delayed hemolytic transfusion reaction - Complications of blood transfusion

\section{Summary}

The risk of hemolytic transfusion reactions (HTRs) is approximately 1:70,000 per unit. Acute HTRs occurring during or within $24 \mathrm{~h}$ after administration of a blood product are usually caused by transfusion of incompatible red blood cells (RBCs), and, more rarely, of a large volume of incompatible plasma. Delayed HTRs are caused by a secondary immune response to an antigen on the donor's RBCs. In some patients with delayed HTRs, an additional bystander hemolysis of the patient's RBCs can be assumed. Different mechanisms lead to intra- and extravascular hemolysis, such as complete complement activation, phagocytosis of RBCs covered with $\mathrm{C} 3 \mathrm{~b}$ by macrophages after incomplete complement activation, or destruction of RBCs covered only with lgG by direct cell-cell contact with $\mathrm{K}$ cells. The clinical consequences of HTRs are triggered via several pathophysiological pathways like formation of anaphylatoxins, release of cytokines causing a systemic inflammatory response syndrome, activation of the kinin system, the intrinsic clotting cascade and fibrinolysis resulting in hypotension, disseminated intravascular coagulation, diffuse bleeding, and disruption of microcirculation leading to renal failure and shock. In the following, the symptoms of HTR are introduced, laboratory investigations and treatment are described, and some recommendations for prevention are given.

\section{Schlüsselwörter \\ Akuter hämolytischer Transfusionszwischenfall . \\ Verzögerte hämolytische Transfusionsunverträglichkeit . Unerwünschte Wirkungen der Bluttransfusion}

\section{Zusammenfassung}

Das Risiko für hämolytische Transfusionsreaktionen (HTR) wird auf etwa 1:70 000 pro Einheit geschätzt. Akute HTR treten während oder bis zu $24 \mathrm{~h}$ nach Transfusion auf und werden meist durch die Gabe inkompatibler Erythrozyten sowie seltener durch die Verabreichung großer Mengen unverträglichen Plasmas verursacht. Verzögerte HTR werden durch eine sekundäre Immunantwort gegen ein Antigen auf den Spendererythrozyten ausgelöst. In einigen Fällen verzögerter HTR kann eine zusätzliche "Bystander»-Hämolyse von Patientenerythrozyten vermutet werden. Verschiedene Mechanismen führen zur intra- und extravasalen Hämolyse, wie eine vollständige Komplementaktivierung, die Phagozytose von C3b-beladenen Erythrozyten durch Makrophagen bei unvollständiger Komplementaktivierung oder die Zerstörung von IgG-beladenen Erythrozyten durch direkten Zell-Zell-Kontakt mit K-Zellen. Die klinischen Folgen von HTR werden auf verschiedenen pathophysiologischen Wegen ausgelöst, beispielsweise durch die Bildung von Anaphylatoxinen, die Freisetzung von Zytokinen, die eine systemische Entzündungsreaktion bewirken, die Aktivierung des Kinin-Systems, der intrinsischen Gerinnungskaskade und der Fibrinolyse, die zu Blutdruckabfall, disseminierter intravasaler Gerinnung, diffusen Blutungen und Mikrozirkulationsstörungen mit der Folge von Nierenversagen und Schock führen können. Im Folgenden werden die Symptome einer HTR vorgestellt, die Diagnostik und Therapie beschrieben und Hinweise zur Prävention gegeben.

\section{KARGER}

Fax +497614520714

Information@Karger.de

www.karger.com
() 2008 S. Karger GmbH, Freiburg

Accessible online at:

www.karger.com/tmh

PD Dr. med. Dr. phil. Erwin Strobe

Department Medizinische Mikrobiologie, Immunologie und Krankenhaushygiene

Medizet, Städtisches Klinikum München $\mathrm{GmbH}$

Kölner Platz 1, 80804 München, Germany

Tel. +49 89 3068-3360, Fax -3835

erwin.strobel@klinikum-muenchen.de 


\section{Introduction}

Complications of blood transfusion may be divided into 2 categories corresponding to the time of the appearance of the first symptoms [1]: acute reactions that occur during or within $24 \mathrm{~h}$ after blood transfusion, and delayed complications that occur later than 1 day after administration of the blood product. With regard to the cause of the adverse event, infectious complications may be distinguished from non-infectious complications, and the latter further divided into immunologic and non-immunologic complications [1]. Immunologic adverse events can be caused by a cellular immune response (e.g. transfusion-associated graft-versus-host disease) or by an antigen-antibody reaction. Antibodies can be directed against all kinds of blood cells, such as red blood cells (RBCs), leukocytes, or platelets. From a clinical point of view, hemolytic transfusion reactions (HTRs) caused by antibodies against $\mathrm{RBC}$ antigens can be distinguished from non-hemolytic adverse events, such as febrile non-hemolytic reactions or allergic reactions.

The consequences of an incompatible transfusion cover a broad spectrum: in some cases the patient only becomes immunized with alloantibodies bearing a potential risk for later transfusions or gravidities. Sometimes, serological tests (e.g. direct antiglobulin test (DAT)) become positive after the transfusion without any clinical symptoms. In other cases, the therapeutic effect of the transfusion (e.g. rise of the patient's hemoglobin value) is missing or too short lasting, but in a number of cases, severe or life-threatening disorders occur. The reasons for HTRs may be human error (e.g. misidentification of a patient, blood product, or blood sample) or are unavoidable (e.g. delayed HTR caused by a very weak antibody that could not be detected at the time of cross-match), whereas technical defects seem to be less frequent [2]. In some cases, several minor mistakes lead to major damage. Critical incident reporting (of near complications) and evaluation of adverse transfusion reactions shall not have the aim to find a guilty person but to reveal the cause of a transfusion reaction in order to treat the patient adequately and to find potential for improvement to prevent the occurrence or repetition of an adverse event.

\section{Epidemiology}

HTRs are the most feared noninfectious complications of blood transfusion, because they were responsible for the greatest part of transfusion-associated deaths from 1976 to 1985 in the USA [3]: 355 transfusion-associated fatalities were reported to the FDA, out of them 327 (including some infections) could be attributed to blood transfusion. 158 cases $(48 \%)$ were caused by acute (immunological) hemolysis, 26 cases $(8 \%)$ by delayed (immunological) hemolysis, and 6 cases (2\%) by non-immunological hemolysis. 131 cases $(83 \%)$ of acute hemolysis were due to ABO compatibility errors, 124
(95\%) of them caused by an incompatible RBC transfusion. Since about 100 million units of RBCs were given to about 30 million patients in this 10 -year period in the USA, the minimum risk of lethal HTRs is approximately 1:550,000 per unit ( $\mathrm{RBC}$ concentrate or whole blood), but may be underestimated because of underreporting.

In the UK, 34 HTRs were reported in 2006 (11 acute HTRs (32\%), 23 delayed HTRs (68\%); no fatality related to the transfusion reaction) [4]. Furthermore, 8 cases of ABO-incompatible RBC transfusions were reported; 2 of them suffered major morbidity, but no patient died. In the following, these 8 cases are added to the 34 cases of HTR. As about 3,000,000 units of blood components were issued in the UK in that year, the risk of HTR can be estimated at about 1:70,000 per unit (all blood components). For comparison, in Germany, the risk of an undetected infectious donation entering the blood supply was estimated in 2001/2002 for human immunodeficiency virus (HIV) to be 1:5,540,000 and for hepatitis $\mathrm{C}$ virus (HCV) to be 1:4,400,000 [5]. For Germany, no data about the incidence of lethal or non-lethal HTRs are available, because reports of inappropriate use of blood components (e.g. ABO incompatibility) are not stipulated by the German transfusion law [6].

\section{Etiology}

HTRs are defined by an accelerated RBC destruction, either of the transfused RBCs, the recipient's RBCs, or - in special cases of delayed hemolytic transfusion reactions - both. Hemolysis may be caused by interaction of antibodies in the recipient's plasma with antigens on the donor's RBCs (major incompatibility), of antibodies in the donor's plasma with antigens on the recipient's RBCs (minor incompatibility), or in rare cases of antibodies in the donor's plasma with antigens on the RBCs of another donor that meet each other in the recipient's blood (inter-donor incompatibility).

Acute HTRs can be caused by incompatible RBCs (from RBC concentrate, granulocyte concentrate, and - historically from whole blood) given to a recipient with regular antibodies, i.e. isoantibodies anti-A and/or anti-B, in the case of an $\mathrm{ABO}$ mistake, or with irregular alloantibodies induced by former blood transfusion or gravidity that are directed towards antigens other than $\mathrm{ABO}$ on the donor's RBCs. In the 1976-1985 series of transfusion-associated deaths in the USA, only 9 of 158 fatal cases of acute hemolysis were due to antibodies other than ABO: 5 due to anti-K, 1 due to anti-Fy, 1 due to anti-Jk ${ }^{\mathrm{b}}$, and 2 due to mixed antibodies including anti-Jk ${ }^{\mathrm{a}}$, anti-Jk ${ }^{\mathrm{b}}$ and anti-Jk3 in one case and anti-E and anti$\mathrm{K}$ in the other case [3]. Less frequently, an acute HTR may be caused by antibodies in the donor's plasma (from fresh frozen plasma (FFP), platelet concentrate (PC), immunoglobulin concentrate, rarely non-recombinant coagulation factor (F VIII) concentrate, or - historically - whole blood) that are directed against the ABO antigens on the patient's RBCs [7, 
8]. Irregular antibodies of the donor are less important because of their generally lower titer than ABO isoantibodies and the dilution in the recipient's plasma. Isoantibodies in the supernatant of RBC concentrates are without adverse effects as the amount of donor plasma in RBC concentrates with additive solution is small (e.g. about $30 \mathrm{ml}$ ), and the antibodies are diluted in the additive solution and after transfusion in the patient's plasma. Moreover, in the case of an ABO-minor-incompatible massive transfusion, the recipient's RBCs are replaced more and more by donor RBCs. Also, an inter-donor incompatibility (e.g. if RBC concentrates of the patient's original blood group are given after an exchange transfusion with group O RBCs) causing an acute HTR is unlikely, if RBC concentrates with additive solution and small residual plasma volume are given and FFPs and PCs have been selected to be ABO-minor-compatible. Moreover, a positive crossmatch would indicate such an improbable incompatibility, provided that a new blood sample is used for laboratory testing.

A special situation may exist in patients after blood stem cell or bone marrow transplantation, and sometimes also after solid organ transplantation. Transmission of donor RBCs or donor plasma together with the transplant can be avoided by preparation procedures. However, if donor B lymphocytes have been transmitted together with the transplant, they may produce isoantibodies, in rare cases also irregular antibodies, in the recipient [9-11]. In the case of 'minor incompatibility' to the recipient's RBCs, this passenger lymphocyte syndrome may cause hemolysis, and in the case of (inter-donor) incompatibility to transfused RBCs also a HTR.

Delayed HTRs are characteristically caused by a secondary immune response to an antigen on the donor's RBCs: if a patient had been immunized a long time before, the titer of an irregular alloantibody may have decreased so that it cannot be found by antibody screening or cross-match at the time of transfusion. In contrast to a primary immune response lasting several weeks to months and producing antibodies of the IgM class at first, a secondary immune response yields antibodies of the IgG class within 3-7 days and in high quantities. At that point of time, a great amount of donor RBCs are often still in the recipient's bloodstream. These RBCs now can be destroyed by the boostered antibodies. Delayed HTRs can be caused by irregular alloantibodies against a lot of RBC antigens, most commonly of the Rhesus, Kidd, Duffy, Kell, and MNSs system: In the 1976-1985 series of transfusion-associated deaths in the USA, 26 fatal cases of delayed hemolysis were reported. Antibodies responsible for incompatibility often had the following specificities: 11 anti-c, 9 anti-E, 7 anti$\mathrm{Jk}^{\mathrm{a}}, 7$ anti-K, 6 anti-Fy ${ }^{\mathrm{a}}, 3$ anti-Jk ${ }^{\mathrm{b}}, 2$ anti-M, 2 anti-s, 1 anti$\mathrm{Fy}^{\mathrm{b}}, 1$ anti-Fy3, 1 anti-Kp ${ }^{\mathrm{a}}, 1$ anti-N, and 1 anti-U (in 16 cases mixtures of these antibodies) [3]. As a secondary immune response is the cause for all delayed HTRs, they are always major incompatibilities.

Recently, attention has been drawn to the facts that in some cases of delayed HTR the DAT is positive for a longer time than would be expected by the survival of the transfused RBCs, or that the extent of the drop in the patient's hemoglobin value may exceed the amount of donor RBCs still present in the patient's bloodstream [12]. Especially in patients with sickle cell anemia, this has been seen more frequently (sickle cell hemolytic transfusion reaction syndrome) [13]. There are several possible explanations for this phenomenon: bystander hemolysis of the patient's autologous RBCs that may be caused by cross-reacting alloantibodies or by autoantibodies induced by the immune response, or suppression of erythropoiesis in combination with the hemolytic reaction [14].

\section{Pathophysiology}

HTRs can involve intravascular and extravascular RBC destruction $[15,16]$. After formation of an antigen-antibody complex, the classical pathway of complement activation may be started. If complement activation on the RBC surface is complete, the resulting membrane attack complex (C5b6789) will cause intravascular hemolysis. If complement activation is stopped before at the level of C3b, RBCs covered with IgG and $\mathrm{C} 3 \mathrm{~b}$ will be bound and destroyed by macrophages, predominantly in the liver. Destruction of RBCs covered with $\mathrm{C} 3 \mathrm{~b}$ alone is much less effective. If no complement activation is induced and RBCs are coated only with $\mathrm{IgG}$, they are removed from circulation mainly in the spleen. Such RBCs can also be bound and destroyed by macrophages, but another mechanism of destruction might act by direct cell-cell contact with large lymphocytes (K cells) releasing perforins (antibodydependent cellular cytotoxicity (ADCC)). Intravascular and extravascular hemolysis can be found in acute HTRs as well as in delayed HTRs. In most cases, both will be present but may predominate differently.

The way and extent of hemolysis are influenced by several points $[15,16]$ : the immunoglobulin class and subclass of the involved antibody are important for the above mentioned mechanisms of RBC destruction (IgM, IgG3, and IgG1 are able to start the classical pathway of complement activation, IgG3 and IgG1 also can initiate extravascular RBC clearance without complement activation). Furthermore, the immunoglobulin class is important for the optimal binding temperature of the antibody: most IgM antibodies prefer temperatures lower than body temperature for binding to RBCs. Hence, they do not (or only at a very low level) activate complement and therefore are not relevant for HTRs, whereas IgG antibodies bind well at $37{ }^{\circ} \mathrm{C}$ to RBCs. The specificity of the antibody is important because the density of the corresponding antigen on the RBC surface influences complement activation as the distance between the bound $\mathrm{IgG}$ molecules on the RBC membrane must be small enough for the complement molecule $\mathrm{C} 1 \mathrm{q}$ to bind to $2 \mathrm{Fc}$ parts of immunoglobulin molecules to start the classical pathway of complement activation. And the more antigen-antibody complexes are formed on the RBC 
surface, the more sites for complement activation resulting in membrane attack complexes are available. This may be one reason for the clinical severity of many of the ABO incompatibilities, as the number of $\mathrm{ABO}$ antigens on RBCs (except for some weak A subgroups) is much greater than that of many other antigens (e.g. Rh antigens). Finally, the titer of the antibody and the amount of incompatible RBCs are relevant for the clinical sequelae of HTRs: for example in the situation of an $\mathrm{ABO}$ major incompatibility, a low number of donor RBCs is attacked by a large amount (high titer) of preexisting antibodies in the patient's plasma, whereas in the situation of a ABO minor incompatibility, the donor's antibodies are diluted in the recipient's plasma and distributed over a large number of RBCs. Therefore, even a small volume of ABO incompatible RBCs (as little as $10 \mathrm{ml}$ ) can cause clinical symptoms in an awake patient [1]. Larger volumes of incompatible blood will intensify the severity of the disorder to the point of life-threatening or lethal consequences. As delayed HTRs are caused by antibodies other than anti-A or anti-B, and the amount of the boostered irregular antibody is growing over several days, hemolysis is usually slower and clinical symptoms often milder. Nevertheless, in some rare cases, the clinical course may be severe.

The clinical consequences of HTRs are triggered via several pathophysiological pathways $[1,15,17,18]$. In principle, they may be the same for acute and delayed HTRs, but less severe in the latter, as mentioned above. By intravascular RBC destruction, hemoglobin is released into the plasma and bound by haptoglobin, hemopexin, and albumin. If their absorption capacity is exceeded, free hemoglobin passes through the glomeruli and is reabsorbed by the renal tubuli. If this reabsorption capacity is also exceeded, free hemoglobin can be found in the urine. But in contrast to earlier ideas, excretion of free hemoglobin by the kidneys seems not to be the major cause of renal failure in HTRs. Hemoglobin released by intravascular hemolysis and bound to haptoglobin is broken down in the reticulo-endothelial system, as well as hemoglobin released from RBCs destroyed by phagocytosis in extravascular hemolysis. This is followed by a rise in indirect bilirubin, and prehepatic icterus. In the case of massive intravascular hemolysis, hyperkalemia may occur, especially if renal function is disturbed. By the classical pathway of complement activation, the anaphylatoxins $\mathrm{C} 3 \mathrm{a}$ and $\mathrm{C} 4 \mathrm{a}$, in the case of complete complement activation also C5a, are formed in HTRs. They release histamine and serotonine from mast cells causing vasodilatation, leakage of plasma through vascular endothelium, and consequent hypotension. A lot of cytokines are released from leukocytes stimulated by intravascular as well as extravascular hemolysis, e.g. IL-1, TNF, IL-6, IL-8, and MCP. They cause a systemic inflammatory response syndrome with fever, hypotension, mobilization of leukocytes from bone marrow, induction of adhesion molecules, and release of tissue factor from endothelial cells as well as activation of neutrophils leading to protease release causing endothelial damage. Acti- vation of FXII (Hageman factor) by immune complexes and by circulating RBC stroma has several consequences, such as activation of the kallikrein-kinin system, the intrinsic clotting cascade, and fibrinolysis. Activation of kallikrein from prekallikrein leads to generation of bradykinin and kallidin from high and low molecular weight kininogen. These kinins increase capillary permeability and cause arteriolar dilatation, resulting in hypotension and deterioration of microcirculation. Disseminated intravascular coagulation (DIC) is not only triggered by activation of the clotting cascade through FXIIa, but also by thromboplastic material released from activated leukocytes, platelets, and damaged endothelial cells. In consequence, DIC triggers disruption of microcirculation by formation of microthrombi, leading to ischemic damage of tissues. Furthermore, consumption of coagulation factors and platelets occurs, which can, in combination with activation of the fibrinolytic system by FXIIa, cause diffuse bleeding. Hypotension provokes a neuroendocrine response including release of catecholamines and activation of the sympathetic nervous system. This leads to vasoconstriction in organs rich in vascular alphaadrenergic receptors, such as kidneys, lung, gastrointestinal tract, and skin. Hypotension, vasoconstriction, and DIC can cause hypoperfusion of these organs, disturbance of their function, and ischemic necrosis, if prolonged. According to current knowledge, this is also the main cause of renal failure in severe HTRs. In the end, progressive shock with multi-organ failure can cause death in untreated HTRs.

\section{Symptoms}

In the beginning, the symptoms of an acute HTR often are not specific $[1,2]$. If the patient is conscious, he may early on suffer from agitation, chills, a burning sensation at the infusion site, pain in the chest, abdomen or in the back, headache, nausea, vomiting, tachypnea and/or dyspnea. Objective symptoms also can be seen in an unconscious patient, e.g. fever (increase of body temperature $>1{ }^{\circ} \mathrm{C}$ ), skin changes (e.g. flushing, edema, or paleness), tachycardia, hypotension, and/or urine color change (transparent reddish color). Diffuse bleeding as a sign of DIC or anuria as the consequence of renal failure may follow. Especially in an anesthetized patient where subjective signs are missing, shock, hemoglobinuria, and systemic hemorrhagic state may be the first symptoms of an acute HTR.

The symptoms of a delayed HTR may be similar to those of an acute HTR, but are often less severe. Indisposition, fever of unknown origin, and clinical signs of anemia may be present. An unexplained fall of the patient's hemoglobin value and mild jaundice about 1 week after blood transfusion can be symptoms of delayed HTR. Sometimes, hemoglobinuria is seen in a delayed HTR, but renal failure is uncommon. Death caused by a delayed HTR is very rare, but in a critically ill patient, delayed HTR may add to other severe restrictions altogether leading to a lethal outcome. In several cases, however, a 
Table 1. Some differential diagnoses of hemolytic transfusion reactions

\section{Immunologically caused hemolysis}

Autoimmunhemolytic anemia

'Warm' antibody induced hemolytic anemia

Cold hemagglutinin disease

Paroxysmal cold hemoglobinuria

Drug induced immune hemolytic anemia

Passenger lymphocyte syndrome after stem cell or solid organ transplantation

Hemolytic disease of the newborn

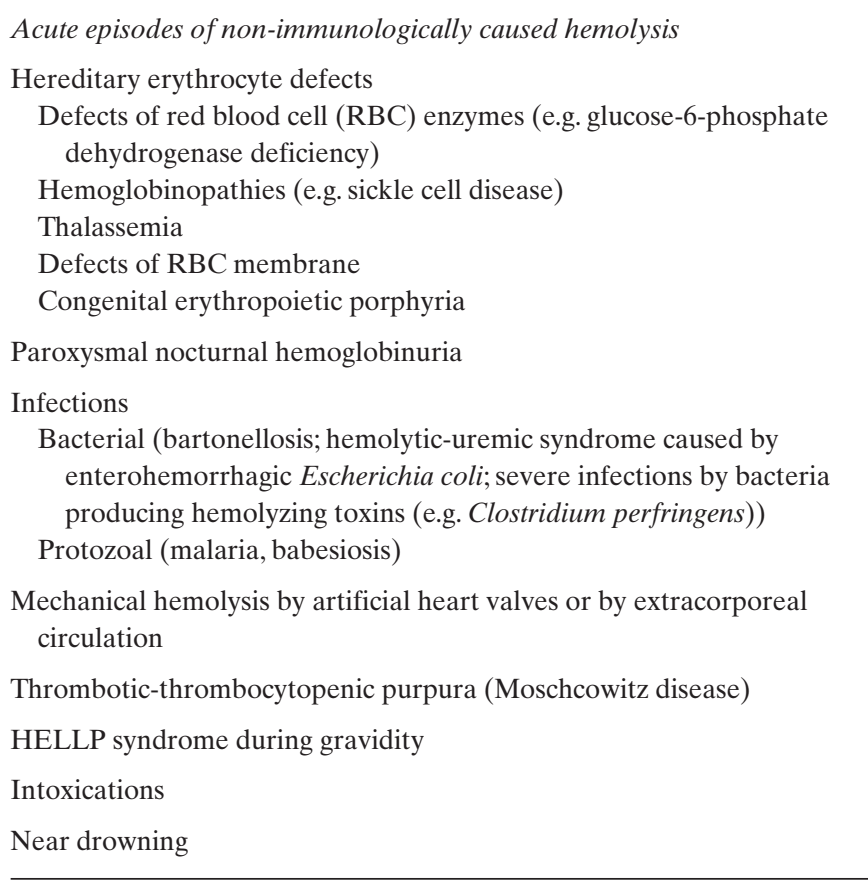

delayed HTR after incompatible RBC transfusion shows no clinical symptoms at all but is only recognized - often by chance - by laboratory investigations like a positive DAT or a previously unknown irregular antibody. In such cases, it might be better to call this a delayed serological transfusion reaction (DSTR) [19, 20].

As other life-threatening complications of blood transfusion (i.e. septic shock due to a bacterially contaminated blood component, anaphylactic reaction in a patient with $\mathrm{IgA}$ deficiency, or transfusion-related acute lung injury) may also begin with similar symptoms as an acute HTR, it is most important to verify or exclude hemolysis if a patient's condition has worsened in connection with administration of a blood product. On the other hand, one should not forget that symptoms arising during or a short time after blood transfusion may also be caused by another disease completely independent from blood transfusion (coincidence but not causality). Therefore, acute hemolysis in a patient may be caused not only by an incompatible blood transfusion but also by a lot of other reasons [21-26] (table 1).

In connection with blood transfusion, symptoms similar to an acute HTR may also be seen in the case of administration of hemolyzed blood. This may occur when RBCs are damaged in the blood bag, e.g. by freezing or heating, chemically by addition of incompatible drugs or solutions, mechanically by incorrect component preparation, by bacterial contamination, or by exceeding the storage time. In such a case, free hemoglobin is already elevated in the blood bag. Hemolysis may also occur when the blood passes through the administration device, e.g. by heating with a defect blood warmer, mechanically by passing through a narrow patch under pressure, or chemically by simultaneous infusion of an incompatible solution. In these cases, elevated free hemoglobin is only found in the administration tubing, but not in the blood bag. In contrast to immunologically caused HTR, in both settings of administration of hemolyzed blood, the patient's DAT is negative (or has not changed between before and after the transfusion) [1,27].

\section{Laboratory Investigations}

In every case of an acute transfusion reaction, hemolysis must be excluded (or proved) immediately. The easiest way is to centrifuge an anticoagulated blood sample of the patient drawn as soon as possible after the event, and to inspect the supernatant for red color. To avoid artificial hemolysis, drawing of the blood sample should be done very carefully without strong suction. Free hemoglobin $>50 \mathrm{mg} / \mathrm{dl}$ usually can be recognized by a reddish color of the plasma. For further investigation, free hemoglobin in the patient's plasma can be quantitatively measured in the laboratory. If the urine is red, hemoglobinuria should be distinguished from hematuria by immediate centrifugation of a freshly drawn urine sample. If the supernatant is transparent and reddish, excretion of free hemoglobin can be suspected and proved in the laboratory by using a test strip. As myoglobin can also cause a reddish color of the plasma and the urine, hemoglobin should be distinguished from myoglobin by means of molecule filtration or electrophoresis in patients with severe muscle injuries. Reduction of the haptoglobin concentration in the plasma is a very sensitive marker for hemolysis, but as it is produced in the liver, it may also be reduced in patients with liver damage; and as it is an acute-phase protein, slight hemolysis might be hidden in patients with acute inflammation. Also, hemopexin in the plasma is reduced by hemolysis, but its reduction is less sensitive than that of haptoglobin. A rise in lactate dehydrogenase (LDH) in the plasma is also indicative for hemolysis, but as it is also contained in many other tissues, e.g. myocard, kidney, lymphatic tissue, platelets, liver, and skeletal muscle, elevated $\mathrm{LDH}$ activity should always be interpreted together with other signs of hemolysis. Beginning $1 \mathrm{~h}$ after acute hemolysis, the bilirubin level also rises in the plasma with a peak at 5-7 $\mathrm{h}$ and normalizing about 1 day after the event. In contrast to intra- and posthepatic icterus, in hemolysis, indirect bilirubin in the plasma is elevated. In the urine, excretion of 
urobilinogen is usually increased, but no excretion of bilirubin is found (can be investigated by test strips) [28-31].

Also, in the case of a delayed HTR, rise in bilirubin, reduction of haptoglobin, and sometimes slightly elevated free hemoglobin in the patient's plasma can be found. In some cases, hemoglobinuria may also occur. The hemoglobin value of the patient will drop again about 1-2 weeks after blood transfusion without bleeding or other known reasons. The reticulocyte count will rise if the patient's disease allows this reaction, and in the blood smear spherocytes can be seen.

For further investigation of an acute HTR, a patient's blood sample drawn after transfusion and the blood bag with the remaining donor blood (and the administration device attached) have to be sent to the laboratory. Also, the patient's pretransfusion blood sample and the donor's blood sample (tube segment) used for the cross-match before transfusion are needed for a complete evaluation. The evaluation of a suspected adverse transfusion reaction should not be performed by the same technician that had done blood grouping and crossmatch before transfusion (to avoid repetition of any mistakes). At first, the DAT of the patient's blood before and immediately after blood transfusion and of the blood from the blood bag is done. If the patient's DAT has become positive (or significantly stronger) after the transfusion, an RBC incompatibility has to be suspected as the reason for the HTR, provided that the donor's RBCs show a negative DAT. The next step is to check the identity (at least by testing $\mathrm{ABO}$ and D) of the patient's pre- and posttransfusion blood samples as well as of the donor's blood from the blood bag and the sample used for cross-match (in the case of a RBC transfusion). If there has been an error in the patient's identification or a sample mix-up or mislabeling of the blood unit, it must be checked at once whether another patient is also at risk to be transfused with a wrong blood product. All false results or records must be revised immediately to avoid further errors. A written report about all the results of the evaluation of a suspected transfusion reaction has to be given to the clinicians.

Further evaluation of a HTR caused by transfusion of a RBC concentrate includes antibody screening tests from the recipient before and after transfusion as well as repetition of the cross-matches with the patient's plasma (before and after transfusion) and the RBCs from the blood bag. If an FFP or a PC has caused the HTR, ABO typing and an antibody screening test of the donor's plasma should be performed as well as a cross-match with the patient's RBCs (before and after transfusion) and the plasma from the blood bag.

If the polyspecific DAT is positive, it should be further examined by monospecific DATs (for immunoglobulins and for complement factors $\mathrm{C} 3 \mathrm{c}$ and $\mathrm{C} 3 \mathrm{~d}$ ), and an antibody elution from the RBCs should be done to identify the antibody. Also, if an antibody screening test in the plasma and/or the crossmatch is positive, antibody identification has to be carried out. If an antibody has been identified in the patient, the absence of the corresponding antigen in the pretransfusion sample in- dicates an alloantibody. To prove that the HTR has been caused by the suspected blood bag, the corresponding antigen has to been shown on the donor's RBCs.

As transfusion of hemolyzed blood may be followed by the same symptoms as an acute HTR, free hemoglobin should be measured in the supernatant from the blood bag and, if negative there, also in the administration tube, if no RBC incompatibility is found. Furthermore, sterility testing of the blood product should be performed, and blood cultures from the patient should be drawn because bacterial contamination of the blood product may cause symptoms similar to a HTR as well as some kinds of bacterial sepsis of the patient independent of blood transfusion. If a HTR is suspected, but no antibody was revealed by the antibody screening test and the cross-match, these tests should be repeated with further blood samples drawn from the patient during the next 2 weeks as the antibody might be boostered by the blood transfusion and found in one of the following blood samples.

In the case of a delayed HTR, a positive DAT and/or antibody screening test may arise some days after blood transfusion. Identification of the 'new' antibody in the patient's plasma or in the eluate can be performed now. To distinguish an alloantibody causing a delayed HTR from a newly formed autoantibody, the corresponding antigen on the patient's pretransfusion blood sample must be investigated. Therefore, it is necessary to keep the blood sample used for cross-match for at least 10 days in the laboratory (stored at $4{ }^{\circ} \mathrm{C}$ ) according to German transfusion guidelines [32 (4.2.4)]. If this blood sample is not yet available, DNA testing of the patient may be helpful in some cases. Thorough evaluation of a suspected case of a delayed HTR is important because the alloantibodies must be taken into account in further blood transfusions to avoid an acute HTR [1, 15, 32 (4.5.1, 4.5.4), 33].

\section{Treatment}

Irrespective of the cause of a severe acute adverse transfusion reaction, at first the transfusion has to be stopped and the venous access maintained by infusion of normal saline $(0.9 \%$ sodium chloride). The patient has to be examined and evaluated immediately by the responsible physician. The identity of the patient and the blood product must be checked, and the $\mathrm{ABO}$ bedside test should be repeated from the patient and additionally from the blood bag. Hemolysis has to be excluded or proved by centrifugation and inspection of a freshly drawn blood sample of the patient as soon as possible. Then, a posttransfusion blood sample from the patient and the blood bag with the rest of its content should be sent to the laboratory for further investigations (see above). To assess the patient's condition, several laboratory parameters should be monitored during the next days: electrolytes $\left(\mathrm{Na}^{+}, \mathrm{K}^{+}\right)$, arterial blood gas status ( $\mathrm{pH}, \mathrm{pO}_{2}, \mathrm{pCO}_{2}, \mathrm{HCO}_{3}{ }^{-}$), coagulation (aPTT, prothrombin time, fibrinogen, antithrombin, fibrin monomers, and D- 
dimers), blood cell counts (RBCs, hemoglobin, hematocrit, white blood cells, and platelets), and serum creatinine [1,2]. Irrespective of the kind of adverse transfusion reaction, corticosteroids (e.g. prednisolone) and antihistamines (e.g. clemastine or dimentiden) are given (intravenously (i.v.)) to relieve the symptoms. If necessary, aspirin-free analgesics and antipyretics (e.g. paracetamol), antiemetics, and/or sedatives are administered [1].

In the case of a severe transfusion reaction, basic life support has to start at once. The patient should be transferred to a critical care unit where his vital parameters (blood pressure, heart rate, respiration) and urine production can be monitored continuously. Hypotension has to be treated vigorously by volume substitution (under control of central venous pressure or pulmonary capillary wedge pressure) and catecholamines (e.g. adrenalin, if blood pressure remains low in spite of volume substitution). Views differ on the effect of dopamine in low doses $(2-5 \mu \mathrm{g} / \mathrm{kg} \cdot \mathrm{min})$, not decreasing the renal blood flow, in this situation [1]. Acidosis should only be balanced cautiously by $\mathrm{NaHCO}_{3}{ }^{-}$i.v., avoiding hypernatremia in the case of reduced renal function. Application of $\mathrm{O}_{2}$, if necessary artificial ventilation, and substitution of compatible RBCs in the case of persisting anemia can help to avoid hypoxic tissue damage. Treatment of DIC should be performed according to the actual laboratory values. Heparin is controversial because of the risk of increased bleeding, and should therefore be omitted. Substitution of antithrombin should be based on an individual risk-benefit assessment, if its level is significantly lowered. Administration of FFPs, fibrinogen, and platelets may be needed to stop diffuse bleeding. Renal failure may be prevented and treated by adequate therapy of shock and maintenance of adequate renal blood flow. Administration of diuretics (i.e. furosemide) in combination with substitution of normal saline i.v. can be tried to improve renal perfusion and urine production. If no diuretic response occurs within a few hours, this therapy should not be continued, but hemofiltration or hemodialysis should be started soon. In a life-threatening case of acute HTR, exchange transfusion with compatible blood might be considered as a last attempt to remove the disintegration products of the damaged RBCs and the RBCs coated with antibodies but not yet destroyed, and to substitute compatible RBCs as oxygen carriers at the same time [1,2,34].

Delayed HTRs often need no therapeutic measures at all. Nevertheless, coagulation status, renal function, and blood cell counts should be monitored. Sometimes, transfusion of compatible RBC concentrates is needed if the patient's hemoglobin is falling. Further treatment is symptomatic (e.g. antipyretics) [1].

\section{Prevention}

As severe acute HTRs are often caused by identification errors (of the patient or the blood product), it is important to check the identity of the patient when a blood sample is drawn for blood grouping or cross-matching as well as when the blood unit is administered [32 (4.2.3)]. Also, in the laboratory, the blood samples of all patients must be identified exactly. At least the ABO blood group of each blood sample for crossmatching has to be tested and compared with earlier results of the patient [32 (4.2.5.9)]. Therefore, it might be better to perform first blood grouping and cross-matching with 2 separately drawn blood samples from the patient. When blood products are issued, they must be clearly assigned to the recipient [32 (4.3.2)]. Immediately before the transfusion is started, the patient's identity has to be checked again, and an ABO bedside test from the patient has to be performed and its result compared with the $\mathrm{ABO}$ blood group of the RBC concentrate [32 (4.3.2.1)]. Also, in connection with the administration of autologous blood products, identification errors can occur. As German transfusion guidelines do not stipulate cross-match of autologous RBC concentrates, the ABO bedside test has to be done before retransfusion not only with the blood of the recipient but also with that from the RBC concentrate [32 (4.6.1)]. A visual examination of the blood product (e.g. for change of color) should also be done before starting the transfusion [32 (4.3.2)]. According to German transfusion guidelines, at the beginning of the transfusion, the patient has to be monitored by a physician [32 (4.3.4)]. After some minutes, the monitoring of the recipient can be continued by a nurse. It should last for the time of the transfusion and for about $1 \mathrm{~h}$ afterwards.

Administration of blood products in emergency situations involves a higher risk of misfits than in routine situations, and should be restricted to really urgent indications [32 (4.3.9)]. As in unconscious patients the risk of identification errors is higher, these patients should be identified very carefully [32 (4.3.2)]. This applies in the same way for situations where several patients have to be transfused at the same time, e.g. in the case of a mass accident. For all aspects of administration of blood products, written procedures should be drawn up, and all staff should be trained in their performing.

As delayed HTRs are caused by boostering of an antibody undetectable at the time of cross-match, irregular antibodies of a patient that have been found at earlier times must be taken into account for selection of RBC concentrates, even if the antibody screening test and the cross-matches are negative now [32 (4.2.5.11)]. The blood sample for cross-matching should not be older than 3 days if the patient had been transfused in the last months, to find irregular antibodies boostered by prior transfusions [32 (4.2.5.9)]. A medical alert card should be issued to all patients in whom irregular antibodies were found so that they can present this information at the time of transfusion in a different medical facility [32 (4.2.5.8)].

To prevent patients from producing new irregular antibodies, $\mathrm{RBC}$ concentrates without those antigens that are not present in the recipient should be selected for transfusion. As this principle cannot be followed for a greater number of antigens because of logistic reasons, the antigens considered should be 
selected by their immunogenicity and their frequency in the population. The latter is responsible for the probability that an antigen-negative recipient will be transfused with blood from an antigen-positive donor if the antigen is not tested and considered, and for the chance to find an antigen-negative $\mathrm{RBC}$ concentrate at a later time if the patient would have produced an irregular antibody against this antigen [35]. Rh antigen D is the most immunogenic antigen (about $20-30 \%$ probability of immunization if a D-positive RBC concentrate is given to a D-negative patient [36]). Therefore, it should be considered for all RBC transfusions except special emergency situations such as an urgent transfusion in a male or a postmenopausal female patient, if D-negative RBC concentrates are not available in time [32 (4.3.5)]. Other antigens like $\mathrm{K}$ and the Rh antigens $\mathrm{C}, \mathrm{c}, \mathrm{E}$, and e are less immunogenic, and can usually only be considered in special patient groups like girls and women before the menopause, patients that will be transfused for a long time (e.g. with sickle cell disease or thalassemia) and patients with irregular alloantibodies or with RBC autoantibodies, because further irregular antibodies would complicate finding suitable $\mathrm{RBC}$ concentrates in the future [32 (4.2.2), 37].

\section{References}

1 Brecher ME (ed): Technical Manual. Bethesda, American Association of Blood Banks, 2005, pp. 633-665.

2 Mollison PL, Engelfriet CP, Contreras M: Blood Transfusion in Clinical Medicine. Oxford, Blackwell, 1993, pp 367, 498-542.

3 Sazama K: Reports of 355 transfusion-associated deaths: 1976 through 1985. Transfusion 1990;30: 583-590.

4 SHOT Annual Report 2006, pp. 13,26, 60-65; www. shot-uk.org/SHOT_report_2006.pdf.

$\checkmark 5$ Offergeld R, Faensen D, Ritter S, Hamouda O: Human immunodeficiency virus, hepatitis $\mathrm{C}$ and hepatitis B infections among blood donors in Germany 2000-2002: risk of virus transmission and the impact of nucleic acid amplification testing. Euro Surveill 2005;10:8-11.

6 Graul A, Heiden M, Gräf K, Keller-Stanislawski B: Hämovigilanz in Deutschland - Berichte an das Paul-Ehrlich-Institut über Verdachtsfälle von Transfusionsreaktionen im Beobachtungszeitraum Januar 1995 bis Dezember 2002. Transfus Med Hemother 2003;30:232-238.

7 Kluge A, Dopfer R, Pfeiffer-Wolf J, Roelcke D: Immunoglobulin high-dose therapy: RBC alloantibodies in commercial preparations and hemolytic anemia: a case report; in Sibrowski W, Stangel W, Wegener S (Hrsg): Transfusionsmedizin 1993/94, Beiträge zur Infusionstherapie und Transfusionsmedizin. Basel, Karger, 1994, vol. 32, pp 474-475.

$\checkmark$ Hach-Wunderle V, Teixidor D, Zumpe P, Kühnl P, Scharrer J: Anti-A in factor VIII concentrate: a cause of severe hemolysis in a patient with acquired factor VIII:C antibodies. Infusionstherapie 1989; 16:100-101

$\checkmark$ Salmon JP, Michaux S, Hermanne JP, Baudoux E, Gerard C, Sontag-Thull D, Fillet G, Beguin Y: Delayed massive immune hemolysis mediated by minor ABO incompatibility after allogeneic peripheral blood progenitor cell transplantation. Transfusion 1999;39:824-827.

10 Leo A, Mytilineos J, Voso MT, Weber-Nordt R, Liebisch P, Lensing C, Schraven B: Passenger lymphocyte syndrome with severe hemolytic anemia due to an anti-Jk(a) after allogeneic PBPC transplantation. Transfusion 2000;40:632-636.

11 Ramsey G: Red cell antibodies arising from solid organ transplants. Transfusion 1991;31:76-86.
12 Salama A, Mueller-Eckhard C: Delayed hemolytic transfusion reactions. Evidence for complement activation involving allogeneic and autologous red cells. Transfusion 1984;24:188-193.

13 Petz LD, Calhoun L, Shulman IA, Johnson C, Herron RM: The sickle cell hemolytic reaction syndrome. Transfusion 1997;37:382-392.

14 Petz LD: Bystander immune cytolysis. Transfus Med Rev 2006;20:110-140.

15 Issitt PD, Anstee DJ: Applied Blood Group Serology. Durham, Montgomery, 1998, pp. 115-163, 907937.

16 Roelcke D: Nichtinfektiöse unerwünschte Wirkungen; in Mueller-Eckhardt C (Hrsg): Transfusionsmedizin. Berlin, Springer, 1996, pp 525-534.

17 Davenport RD, Kunkel SL: Cytokine roles in hemolytic and non-hemolytic transfusion reactions. Transfus Med Rev 1994;8:157-168.

18 Capon SM, Goldfinger D: Acute hemolytic transfusion reaction, a paradigm of the systemic inflammatory response: new insights into pathophysiology and treatment. Transfusion 1995;35:513-520. (Erratum in Transfusion 1995;35:794).

19 Ness PM, Shirey RS, Thoman SK, Buck SA: The differentiation of delayed serologic and delayed hemolytic transfusion reactions: Incidence, long-term serologic findings, and clinical significance. Transfusion 1990;30:688-693.

20 Vamvakas EC, Pineda AA, Reisner R, Santrach PJ, Moore SB: The differentiation of delayed hemolytic and delayed serologic transfusion reactions: incidence and predictors of hemolysis. Transfusion 1995;35:26-32.

21 Strobel E, Nathrath M, Peters J, Abele-Horn M, Wüllenweber J: Akute intravasale Hämolyse bei Clostridium-perfringens-Sepsis. Dtsch Med Wochenschr 1994;119:375-379.

22 Strobel E: Diagnostic importance and difficulties in testing of T-antigen activation. Infus Ther Transfus Med 2002;29:249-252.

23 Dietzfelbinger H: Korpuskuläre hämolytische Anämien; in Begemann H, Rastetter J (Hrsg): Klinische Hämatologie. Stuttgart, Thieme, 1993, pp 248-313.

24 Salama A, Mueller-Eckhardt C: Immunhämolytische Anämien; in Begemann $\mathrm{H}$, Rastetter $\mathrm{J}$ (Hrsg): Klinische Hämatologie. Stuttgart, Thieme, 1993, pp 313-335.
25 Rastetter J: Toxische hämolytische Anämien; in Begemann H, Rastetter J (Hrsg): Klinische Hämatologie. Stuttgart, Thieme, 1993, pp 336-341.

26 Rastetter J: Verschiedenartige hämolytische Anämien; in Begemann H, Rastetter J (Hrsg): Klinische Hämatologie. Stuttgart, Thieme, 1993, pp 342-348.

27 Kiefel V: Nichtinfektiöse unerwünschte Wirkungen; in Mueller-Eckhardt C, Kiefel V (Hrsg): Transfusionsmedizin. Berlin, Springer, 2004, pp 580-586.

28 Bauer K: Freies Hämoglobin; in Thomas L (Hrsg): Labor und Diagnose. Marburg, Medizinische Verlagsgesellschaft, 1992, pp 811-812.

29 Thomas L: Haptoglobin/Hämopexin; in Thomas L (Hrsg): Labor und Diagnose. Frankfurt, TH-Books Verlagsgesellschaft mbH, 1998, pp 679-684.

30 Thomas L: Lactat-Dehydrogenase (LDH); in Thomas L (Hrsg): Labor und Diagnose. Frankfurt, TH-Books Verlagsgesellschaft mbH, 1998, pp 9197.

31 Thomas L: Bilirubin; in Thomas L (Hrsg): Labor und Diagnose. Frankfurt, TH-Books Verlagsgesellschaft mbH, 1998, pp 197-208.

32 Wissenschaftlicher Beirat der Bundesärztekammer und Paul-Ehrlich-Institut: Richtlinien zur Gewinnung von Blut und Blutbestandteilen und zur Anwendung von Blutprodukten (Hämotherapie) gemäß $§ 12$ und 18 des Transfusionsgesetzes (Gesamtnovelle 2005 mit Änderungen und Ergänzungen 2007). BAnz Nr. 209a vom 05.11.2005 und Nr. 92 vom 19.05.2007.

33 Flegel WA, Kubanek B, Northoff H: Abklärung einer Transfusionsreaktion. Dtsch Ärztebl 1990;87: B-860-864.

34 Kolb H: Austauschtransfusion beim Erwachsenen; in Schneider W, Schorer R (Hrsg): Klinische Transfusionsmedizin. Weinheim, Edition Medizin, 1982, pp. 75-85.

35 Schönitzer D: Prätransfusionelle Untersuchungen. Basel, Karger, 1993, pp 119-123.

36 Gonzalez-Porras JR, Graciani IF, Perez-Simon JA, Martin-Sanchez J, Encinas C, Conde MP, Nieto MJ, Corral M: Prospective evaluation of a transfusion policy of D+ red blood cells into D- patients. Transfusion 2008:48;1318-1324.

37 Giblett E: A critique of the theoretical hazard of inter-racial transfusion. Transfusion 1961;1:233-238. 